\title{
Hydroxychloroquine Ocular Toxicity: Lessons Learned
}

JEFF C. RABIN, OD, MS, PhD, Professor and Assistant Dean for Graduate Studies, Research and Assessment, and Chief, Visual Neurophysiology Service, University of the Incarnate Word Rosenberg School of Optometry; KIRSTI RAMIREZ, OD, Optometric Resident, University of the Incarnate Word Rosenberg School of Optometry, San Antonio, Texas, USA. Address correspondence to Dr. J.C. Rabin, Chief, Visual Neurophysiology Service, University of the Incarnate Word Rosenberg School of Optometry, 9725 Datapoint Drive, San Antonio, Texas 78229, USA. E-mail: rabin@uiwtx.edu. De-identified case reports with 3 or fewer patients are exempt from formal review by the University of the Incarnate Word Institutional Review Board (UIW IRB) and do not require informed consent although the patient provided verbal consent. This case report satisfied ethical requirements for submission in accord with the UIW IRB. (J Rheumatol 2019;46:1640-1; doi:10.3899/jrheum.181375)

Hydroxychloroquine (HCQ) is efficacious for various diseases $^{1,2}$, but can produce "bulls-eye" retinopathy that decreases vision even after discontinuance ${ }^{3,4}$. Retinopathy can be present in $7.5 \%$ of patients after 5 or more years of HCQ treatment, increasing to $20 \%$ after 20 years ${ }^{2}$. In 2016, the American Academy of Ophthalmology published new recommendations for the evaluation of $\mathrm{HCQ}$, emphasizing dosage based on body weight $(\leq 5 \mathrm{mg} / \mathrm{kg})^{5}$. We describe a case in which dosage significantly exceeded guidelines.

A 50-year-old Hispanic female was referred from a retinal specialist to our Visual Neurophysiology Service. Her weight was 115 pounds. She was receiving HCQ for systemic lupus erythematosus ( $200 \mathrm{mg}$ twice daily) since 2000 but discontinued in 2017 because of toxicity. Total dosage was $2482 \mathrm{~g}$.
Maximum recommended dosage is $5 \mathrm{mg} / \mathrm{kg} \times 0.454$ $\mathrm{kg} /$ pound $=2.27 \mathrm{mg} /$ pound . The maximum recommended dosage for the patient is 115 pounds $\times 2.27 \mathrm{mg} /$ pound $=261$ $\mathrm{mg} /$ day. Acuity was $20 / 25$, but central visual fields showed paracentral scotomas, cone-specific color vision was decreased, and multifocal electroretinograms (mfERG), which assess retinal function from multiple sites, showed signal reduction and delay. Optical coherence tomography (OCT) showed full thickness and inner retinal thinning. Figure 1a shows fundus views with a bulls-eye pattern of photoreceptor and retinal pigment epithelium degeneration more apparent with fundus autofluorescence (FAF; Figure $1 b$ ), which shows active degeneration in white and cell death in black.

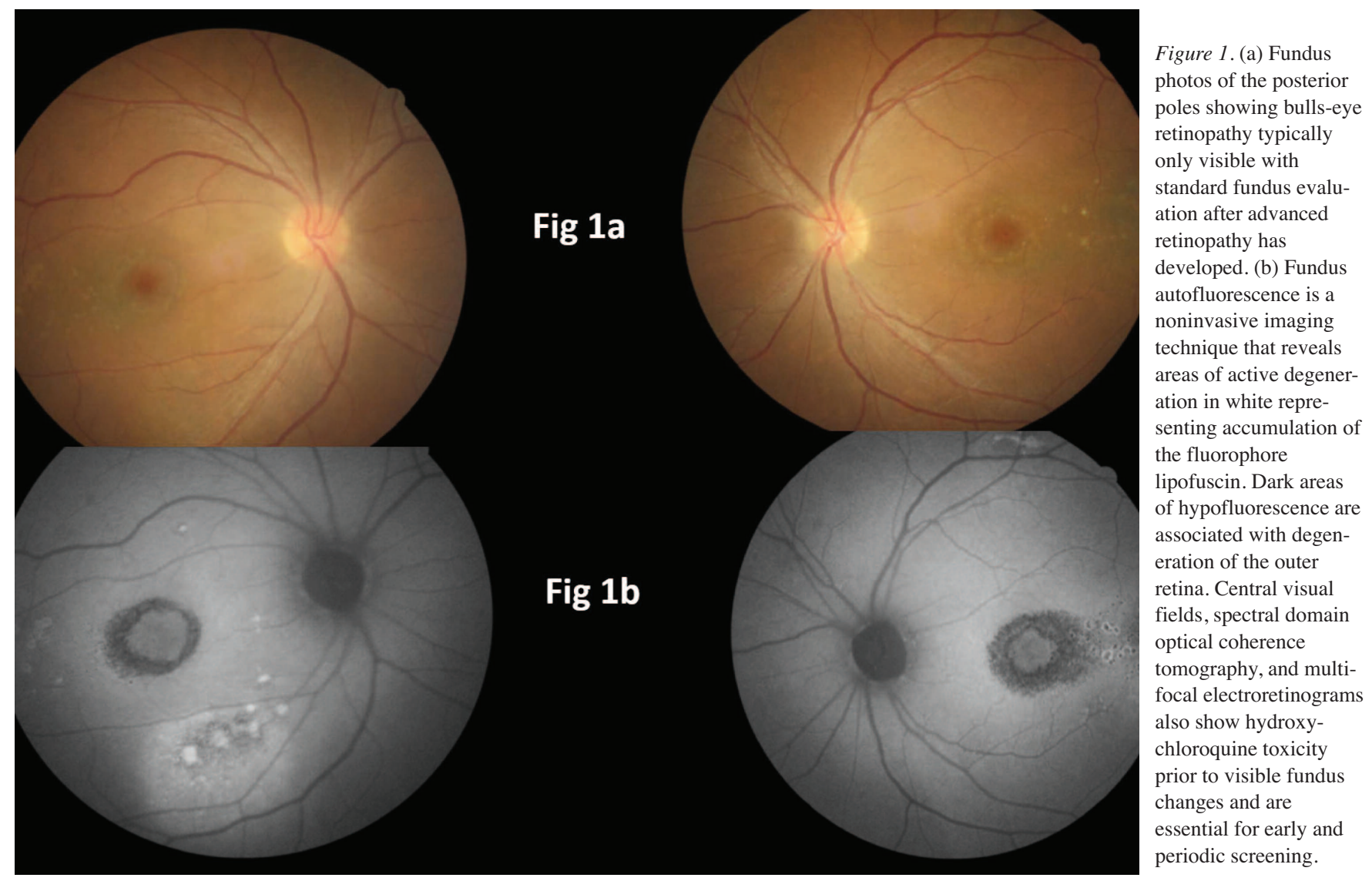

Personal non-commercial use only. The Journal of Rheumatology Copyright $($ C 2019. All rights reserved. 
Weight-based dosage and early screening (central fields, OCT, FAF, mfERG) are essential to prevent HCQ toxicity, particularly with risk factors: small stature, high total dosage, diminished renal function, concomitant tamoxifen use, and/or retinal disease ${ }^{5}$. Interprofessional collaboration is essential to optimize patient outcomes.

\section{REFERENCES}

1. Rynes R. Antimalarial drugs in the treatment of rheumatological diseases. Br J Rheumatol 1997;36:799-805.
2. Yusuf I, Sharma S, Luqmani R, Downes S. Hydroxychloroquine retinopathy. Eye 2017;31:828-45.

3. Pasadhika S, Fishman G. Effects of chronic exposure to hydroxychloroquine or chloroquine on inner retinal structures. Eye 2010;24:340-46.

4. Marmor M, Hu J. Effect of disease stage on progression of hydroxychloroquine retinopathy. JAMA Ophthalmol 2014;132:1105-12.

5. Marmor MF, Kellner U, Lai TY, Melles RB, Mieler WF; American Academy of Ophthalmology. Recommendations on screening for chloroquine and hydroxychloroquine retinopathy (2016 Revision). Ophthalmology 2016;123:1386-94. 